\title{
Mitochondrial phylogeography of the Woodmouse (Apodemus sylvaticus) in the Western Palearctic region
}

\author{
J. R. MICHAUX, ${ }^{*}+$ E. MAGNANOU,+E. PARADIS,+C. NIEBERDING* and R. LIBOIS* \\ *Unité de Recherches Zoogéographiques; Institut de Zoologie; Quai Van Beneden, 22, 4020 Liège, Belgium, +Laboratoire de \\ Paléontologie - cc064; Institut des Sciences de l'Evolution (UMR 5554-CNRS), Université Montpellier II, Place E. Bataillon, 34095 \\ Montpellier Cédex 05, France
}

\begin{abstract}
We sequenced 965 base pairs of the mitochondrial DNA cytochrome $b$ from 102 woodmice (Apodemus sylvaticus) collected from 40 European localities. The aims of the study were to answer the following questions. (i) Did the Mediterranean peninsulas play a role as refuge for woodmice? (ii) Is genetic variability of $A$. sylvaticus higher in the Mediterranean region compared with northern Europe? (iii) Are the patterns of the postglacial colonization of Europe by woodmice similar to those presently recognized for other European species? The results provide a clear picture of the impact of the Quaternary glaciations on the genetic and geographical structure of the woodmouse. Our analyses indicate a higher genetic variability of woodmice in the Mediterranean peninsulas compared to northern Europe, suggesting a role of the former as refuge regions for this small mammal. An original pattern of postglacial colonization is proposed where the Iberian and southern France refuge populations colonized almost all European regions. The Sicilian population appears to be very differentiated and highly variable. This emphasizes the importance of this island as a 'hot spot' for the intraspecific genetic diversity of the woodmouse. Finally, woodmice in North Africa originated from southwestern Europe, most probably as a result of a recent anthropogenic introduction.
\end{abstract}

Keywords: Apodemus sylvaticus, glacial refuge, mtDNA, North Africa, phylogeography, postglacial colonization, Western Palearctic region

Received 21 June 2002; revision received 8 November 2002; accepted 25 November 2002

\section{Introduction}

An increasing number of studies on phylogeographic patterns in European species of plants (i.e. Sharble et al. 2000; Widmer \& Lexer 2001) and different groups of animals such as insects (i.e. Lunt et al. 1998; Mardulyn 2001), amphibians (Szymura et al. 2000), fish (Alexandrino et al. 2000; Engelbrecht et al. 2000; MacHordon et al. 2000), birds (Lucchini \& Randi 1998; Pitra et al. 2000) and several mammals (Bilton et al. 1998; Santucci et al. 1998; Seddon et al. 2001) were recently published.

They have shown the value of molecular genetic data in understanding the effects of Quaternary climatic changes on the intraspecific diversity of European species. During the last 2.4 millions years (Myr), temperate species

Correspondence: J. R. Michaux. Fax: 00334671436 10; E-mail: Johan.Michaux@ulg.ac.be underwent several contractions and expansions of range. This resulted in extinctions of the northern populations during ice ages followed by subsequent northward expansions from southern refugia (mainly the Mediterranean peninsulas) during interglacials (Taberlet et al. 1998). Some major effects on the genetic structure of such environmentally induced range changes were appreciated by Avise (1994) and Hewitt (1996). They hypothesized that rapid expansion from refugial populations involved serial bottlenecking with progressive loss of allelic diversity, resulting in less genetic diversity among populations present in the more recently colonized places. In contrast, it is expected that populations living in the Mediterranean refuge regions were less affected by climatic changes and will be more genetically diversified. This has been observed in the European greenfinch (Carduelis chloris) (Merilae et al. 1997).

Moreover, the isolation of populations of many species in separate southern regions during ice ages led to the 
allopatric differentiation of several genetic groups, which recolonized the Western Palearctic region at the end of the last ice age, 16000 years ago. On the basis of the present distribution of different genetic groups all over Europe, Hewitt $(1999,2001)$ described three patterns of postglacial colonization. In the first one (Chorthippus parallelus pattern), the postglacial expansion originated only from the Balkans. In the second (Erinaceus europaeus pattern), the species colonized northern Europe from three refuge regions: the Iberian peninsula, Italy and the Balkans. Finally, in the third one (Ursus arctos pattern), the species appeared to have colonized most of Europe from two refugia: the Iberian peninsula and the Caucasus/Carpathians.

These studies provide valuable information on the phylogeography of European species. However, several aspects of the influence of the Quaternary climatic fluctuations on the geographical distribution of genetic diversity in Europe remain unclear, particularly for some groups of animals such as small mammals. Firstly, with the exception of the study on hedgehogs (Erinaceus europaeus and E. concolor) (Seddon et al. 2001) and some data on the grasshopper C. parallelus (Hewitt 1999), scant information is available on the level of genetic diversity of animals, particularly comparing southern European regions to northern ones. This kind of information could be very valuable from a conservation biology perspective. Secondly, are recolonization patterns other than those described by Hewitt (1999) likely? Finally, with the exception of the study by Seddon et al. (2001), the studies performed on European small mammals either: (i) did cover the entire distribution range of the species but were based on restricted samples (Taberlet et al. 1998 for Crocidura and Arvicola; Bilton et al. 1998) or (ii) analysed a restricted part of the distribution areas of the species (Taberlet et al. 1994; Jaarola \& Tegelström 1995). This lack of data prevents the drawing of any definitive conclusion concerning the role of the Mediterranean peninsulas as refuges for these species. Indeed, Bilton et al. (1998) proposed that widespread small mammals did not recolonize northern Europe from the Mediterranean peninsulas, which in turn represent 'factories of allopatric speciations'.

The aim of our study is to address these questions in studying a small rodent species, the woodmouse (Apodemus sylvaticus). This species has several advantages for a phylogeographical study. The woodmouse is relatively common, easy to catch and widespread all over the Western Palearctic region. It is a forest species present in the Western Palearctic region for the past 3 Myr. (Michaux \& Pasquier 1974). Therefore, like the forests, it probably survived during the Quaternary glaciations through important fluctuations in its distribution area.

Moreover, the evolutionary history of the genus Apodemus is well known through palaeontological (Michaux \& Pasquier 1974; Michaux et al. 1997) and molecular

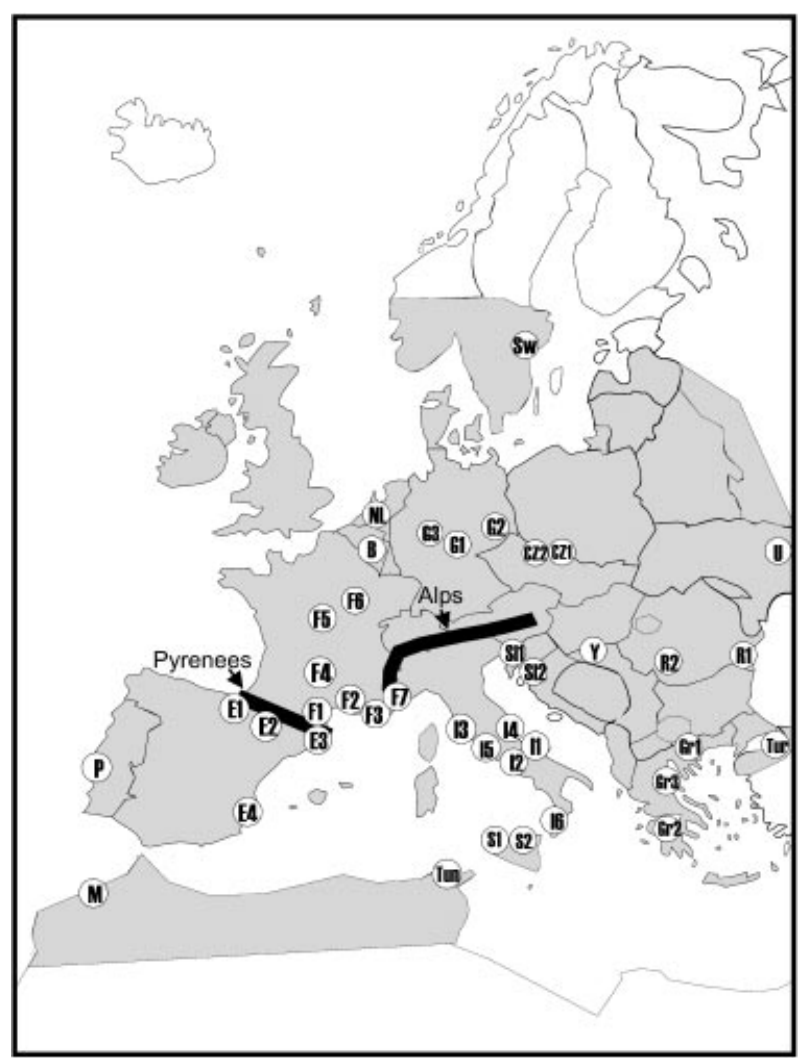

Fig. 1 Geographical distribution of the Apodemus sylvaticus samples. The shaded zone corresponds to the distribution area of the species (as described by Schilling et al. 1986; Zagorodnyuk 1996; and Mezhzherin 1997). Thick lines correspond to the main European biogeographic barriers: the Pyrenees and the Alps. See Table 1 for sample symbols.

phylogenetic (Serizawa et al. 2000; Michaux et al. 2002) studies.

Therefore, a calibration of its molecular clock is possible. This will allow the verification of the importance of the Quaternary ice ages in a possible intraspecific differentiation within $A$. sylvaticus.

Finally, the woodmouse is also distributed in other regions, such as northern Africa or the Mediterranean islands (Fig. 1). The genetic study of specimens from these regions will give new information on their geographical origin.

\section{Materials and Methods}

A total of 102 Apodemus sylvaticus taken from 40 localities throughout its geographical range have been analysed (Table 1, Fig. 1).

DNA was extracted from ethanol-preserved tissue as described by Sambrook et al. (1989). These tissues were taken from the Apodemus tissue collection of J. R. Michaux 
Table 1 Geographic distribution and references of Apodemus tissues used for the experiments

\begin{tabular}{|c|c|c|c|c|}
\hline \multicolumn{2}{|c|}{ Geographic origin } & $\begin{array}{l}\text { Total no. } \\
\text { of animals }\end{array}$ & $\begin{array}{l}\text { Sample symbols } \\
\text { (see Figs 1, } 2 \text { and } 3 \text { ) }\end{array}$ & $\begin{array}{l}\text { Tissue sample or GenBank accession } \\
\text { numbers (for sequenced samples) }\end{array}$ \\
\hline \multicolumn{5}{|c|}{ Apodemus sylvaticus } \\
\hline \multirow[t]{4}{*}{ Spain } & Eugi (Navarre) & 4 & E1 & T-2141, T-2142, T-2143, T-2144 \\
\hline & Torla & 1 & E2 & JRM-700 \\
\hline & Figueras (Catalogna) & 1 & E3 & JRM-578 \\
\hline & Murcia & 4 & $\mathrm{E} 4$ & JRM-594, JRM-596, JRM-714, JRM-715 \\
\hline Portugal & Murtal & 2 & $\mathrm{P}$ & JRM-563, JRM-564 \\
\hline \multirow[t]{7}{*}{ France } & Py Mantet (Pyrénées orientales) & 7 & $\mathrm{~F} 1$ & $\begin{array}{l}\text { JRM-269, JRM-270, JRM-271, JRM-272, JRM-274 } \\
\text { JRM-277, JR -278 }\end{array}$ \\
\hline & Murviel (Hérault) & 3 & $\mathrm{~F} 2$ & JRM-574, JRM-575, JRM-577 \\
\hline & Cap Lardier (Var) & 4 & F3 & JRM-142 to JRM-145 \\
\hline & Sérandon (Corrèze) & 1 & $\mathrm{~F} 4$ & JRM-396 \\
\hline & Allier & 1 & F5 & $\mathrm{T}-665$ \\
\hline & Morvan & 1 & F6 & JRM-589 \\
\hline & Alpes Maritimes & 1 & F7 & JRM-584 \\
\hline \multirow[t]{6}{*}{ Italy } & Penne (Abruzzo) & 4 & I1 & JRM-163, JRM-164, JRM-165, JRM-167 \\
\hline & Rome (Latium) & 1 & $\mathrm{I} 2$ & JRM-168 \\
\hline & Grosseto (Toscania) & 1 & I3 & JRM-176 \\
\hline & San Polo (Latium) & 1 & $\mathrm{I} 4$ & JRM-171 \\
\hline & Tarquinia (Toscania) & 3 & I5 & JRM-172, JRM-173, JRM-174 \\
\hline & Aspromonte (Calabria) & 4 & I6 & JRM-159 to JRM-162, JRM-851 to JRM-860 \\
\hline \multirow{2}{*}{ Sicily } & Alia (Center Sicily) & 3 & S1 & JRM-304 to JRM-306 \\
\hline & Madonia Forest (northern Sicily) & 12 & S2 & JRM-868 to JRM-879 \\
\hline Belgium & Ardennes & 7 & $\mathrm{~B}$ & $\begin{array}{l}\text { JRM-101, JRM-102, JRM-103, JRM-104, JRM-105, } \\
\text { JRM-106, JR M-107 }\end{array}$ \\
\hline Netherlands & & 1 & NL & АВО33695 \\
\hline \multirow[t]{3}{*}{ Germany } & Dresden (Saxony) & 2 & G1 & JRM-515, JRM-519 \\
\hline & Leipzig (Saxony) & 1 & G2 & JRM-514 \\
\hline & Bielefeld & 1 & G3 & JRM-157 \\
\hline \multirow[t]{2}{*}{ Czech Republic } & Kasperske & 3 & CZ1 & JRM-372 to JRM-374 \\
\hline & Klinec jiloviste & 1 & $\mathrm{CZ2}$ & JRM-375 \\
\hline Sweden & Uppsala & 3 & Sw & JRM-452, JRM-453, JRM-455 \\
\hline Yugoslavia & Susarra (Vojvodine) & 3 & $\mathrm{Y}$ & JRM-210 to JRM-212 \\
\hline \multirow[t]{2}{*}{ Slovenia } & Skofja & 1 & Sl1 & JRM-417 \\
\hline & Ljubljana (Vecnapot) & 2 & $\mathrm{Sl} 2$ & JRM-434, JRM-436 \\
\hline Ukraine & Tchernobyl & 4 & $\mathrm{U}$ & AF127536, 37, 38, 43 \\
\hline \multirow[t]{3}{*}{ Greece } & Macedonia & 1 & Gr1 & JRM-181 \\
\hline & Péloponnèse & 1 & Gr2 & JRM-183 \\
\hline & Central Greece & 1 & Gr3 & JRM-705 \\
\hline \multirow[t]{2}{*}{ Romania } & Cheile Garlistei & 1 & $\mathrm{R} 1$ & JRM-570 \\
\hline & constanta county & 1 & $\mathrm{R} 2$ & JRM-571 \\
\hline Turkey & Caycuma (Zonjuldak) & 1 & Tur & JRM-184 \\
\hline Tunisia & Ain Dram & 4 & Tun & JRM-138 to JRM-141 \\
\hline Morocco & Ket ama & 4 & $\mathrm{M}$ & JRM-138 to JRM-141 \\
\hline \multicolumn{5}{|c|}{ Apodemus flavicollis } \\
\hline Italy & Abruzzos & 1 & & AJ311150 \\
\hline France & Allier & 1 & & AJ311151 \\
\hline \multicolumn{5}{|c|}{ Apodemus mystacinus } \\
\hline \multicolumn{2}{|c|}{ Syria } & 1 & & AJ311146 \\
\hline \multicolumn{2}{|l|}{ Greece } & 1 & & AJ311147 \\
\hline \multicolumn{5}{|c|}{ Apodemus agrarius } \\
\hline \multicolumn{2}{|l|}{ Estonia } & 1 & & AJ311144 \\
\hline \multicolumn{2}{|l|}{ Czech Republic } & 1 & & AJ311145 \\
\hline
\end{tabular}


(JRM-numbers) and the mammal tissue collection housed at the Institut des Sciences de l'Evolution de Montpellier (Catzeflis 1991; T-numbers).

By modifying the universal polymerase chain reaction (PCR) primers L7 (5'-ACCAATGACATGAAAAATCATCGTT3') and H16 (5'-ACATGAATYGGAGGYCAACCWG-3'), originally described by Kocher et al. (1989), 965 base pairs of cytochrome $b$ were amplified. Amplification reactions were carried out in $2 \times 50 \mu \mathrm{L}$ volumes including $25 \mu \mathrm{L}$ of each $2 \mu \mathrm{M}$ primer, $20 \mu \mathrm{L}$ of $1 \mathrm{~mm}$ dNTP, $10 \mu \mathrm{L}$ of $10 \times$ reaction buffer, $10 \mu \mathrm{L}$ of purified water and $0.2 \mu \mathrm{L}$ of $5 \mathrm{U} / \mu \mathrm{L}$ Promega Taq DNA polymerase. Approximately $200 \mathrm{ng}$ of DNA extract $(10 \mu \mathrm{L})$ was used per PCR amplification. Amplifications were performed in a Labover PTC100 thermal cycler employing 33 cycles $\left(20 \mathrm{~s}\right.$ at $94^{\circ} \mathrm{C}, 30 \mathrm{~s}$ at $50{ }^{\circ} \mathrm{C}$ and $1 \mathrm{~min} 30 \mathrm{~s}$ at $68^{\circ} \mathrm{C}$ ) with a final extension cycle of $10 \mathrm{~min}$ at $68^{\circ} \mathrm{C}$. PCR products were purified using the Ultra-free DA Amicon kit (Millipore) and directly sequenced. Both strands were sequenced using a Bigdye terminator (Applied Biosystems) sequencing kit on an ABI 310 (Applied Biosystems) automated sequencer.

\section{Sequence alignment and saturation analysis}

The published cytochrome $b$ sequences for $A$. sylvaticus $(n=5:$ AF127543, AF127538, AF127537, AF127536 and ABO33695), A. flavicollis ( $n=2:$ AJ311150 and AJ311151) and $A$. mystacinus $(n=2$ : AJ311146 and AJ311147) were downloaded from GenBank (see Table 1) and aligned to the new sequences using the ED editor [MUST package (Philippe 1993)].

The cytochrome $b$ aligned sequences were analysed for saturation as described by Philippe \& Douzery (1994) and Hassanin et al. (1998). Using the matrices of patristic and inferred substitutions calculated by PAUP 4 (Swofford 1998), the pairwise numbers of observed differences were plotted against the corresponding values for inferred substitutions (Philippe \& Douzery 1994). The slope of the linear regression (S) was used to evaluate the level of saturation (Hassanin et al. 1998). When no saturation is observed in the data set, the slope equals one, whereas the slope tends towards zero as the level of saturation increases.

\section{Analyses}

The aligned sequences were analysed by distance [neighbour joining (NJ); Saitou \& Nei 1987] and by maximum parsimony (MP; Fitch 1971) methods. We used PAUP 4.0b8 [NJ: minimum evolution (ME) criterion, Kimura's two parameter $(\mathrm{K} 2 \mathrm{P})$ distance estimator; MP: heuristic search, tree bisection reconnection (TBR) branch swapping option, Maxtrees = 1000 (Swofford 1998)]. The NJ analysis was performed assuming a gamma distribution for substitution rates across sites, where the parameter alpha
(Yang 1996) and the proportion of invariant sites (I) were estimated with the maximum-likelihood method assuming the $\mathrm{K} 2 \mathrm{P}$ phylogeny using PAUP $4.0 \mathrm{~b} 8$. The robustness of inferences was assessed by bootstrap resampling (BP) (Felsenstein 1985) (1000 and 100 random repetitions for distance and MP analyses, respectively). A minimum spanning network was constructed using the MINSPNET algorithm available in the ARLEQUIN 2.0 program (Schneider et al. 2000). Nucleotide diversity, $\pi$, was estimated using the DNASP program (Rozas \& Rozas 1997). A 'mismatch distribution' of substitutional differences between pairs of haplotypes was calculated within the main genetic lineages and compared with a fit to the Poisson model using DNAsP (Rozas \& Rozas 1997). We used a coalescent approach to validate the patterns of population growth or stability revealed by the mismatch distributions (Emerson et al. 2001). We used maximum likelihood to fit two models, assuming either that the population was stable through time, or that it grew (or declined) exponentially (Kuhner et al. 1995, 1998). Since both models are nested, they were compared with a likelihood-ratio test which follows a $\chi^{2}$ distribution with one degree of freedom (there is an additional parameter in the latter model). This analysis was performed with the programs COALESCE and FLUCTUATE from the package LAMARC (http://evolution.genetics.washington.edu/ lamarc.html). A model of DNA evolution with a transition/tranversion ratio equal to 2 was used with the empirical base frequencies (the results were not sensitive to this last parameter as they were similar if it is assumed that the base frequencies are equal to 0.25 ). The programs were run several times with different numbers of short and long Markov chains to check the consistency of the estimated parameters. The other parameters $(\theta$ with COALESCE, and $\theta$ and the population growth rate with FLUCTUATE) were allowed to vary, and were estimated at the maximum likelihood. The likelihood-ratio test was computed with twice the difference in the log-likelihoods provided by both programs: the null hypothesis being that the population was stable. This analysis was performed separately for the four subclades (1a, 1b, 2a and $2 b$ ).

The population genetic structure was determined by analysing the molecular variance and calculating $\phi_{\mathrm{ST}}$ [analysis of molecular variance (AMOVA) available in ARLEQUIN 2.0; Schneider et al. 2000]. This method estimates the proportion of genetic variation at different hierarchical levels, using information from the geographical distribution of haplotypes and the pairwise distance between them. This analysis was performed at different hierarchical levels: among groups (corresponding to the observed subclades), among populations within each group (17 populations were defined according to geographical and ecological data) and within each population. 
As populations of recent origin may not be at genetic equilibrium, the estimate of the timing of intraspecific divergence must be interpreted cautiously. Therefore, an approximate timing of divergence between the observed mitochondrial DNA (mtDNA) lineages was calculated on the basis of the percentage of genetic divergence obtained with a distance analysis (K2P estimator). As proposed by Edward (1997), the genetic distance between two different lineages was corrected for ancestral mtDNA polymorphism using the formula:

$P_{\text {net }}=P_{A B}-0.5\left(P_{A}+P_{B}\right)$

Where $P_{\text {net }}$ is the corrected distance between the isolated lineages $A$ and $B, P_{A B}$ is the mean genetic distance in pairwise comparisons of individuals from $A$ vs. $B$, and $P_{A}$ and $P_{B}$ are mean genetic distance among individuals within these lineages. Two calibration points derived from palaeontological data were used for this analysis. First, the divergence time between $A$. mystacinus and all the 'small' Sylvaemus was estimated at approximately 7 Myr (Aguilar \& Michaux 1996; Michaux et al. 1997) and second, the divergence between $A$. sylvaticus and A. flavicollis was estimated from fossil data to be approximately 4 Myr (Michaux \& Pasquier 1974; J. Michaux, personal communication).

To identify whether there were differences in the rates of cytochrome $b$ changes in different $A$. sylvaticus lineages or between studied specimens, relative-rate tests were conducted with each of them against the remaining lineages or individuals. The relative-rate tests were performed with RRTREE, version 1.0 (Robinson et al. 1998), which improves the test of $\mathrm{Wu} \& \mathrm{Li}$ (1985) taking into account taxonomic sampling and phylogenetic relationships. The NJ tree was chosen as the reference topology. Apodemus flavicollis was used as an outgroup. Relative-rate tests were performed on the proportions of synonymous $\left(K_{\mathrm{s}}\right)$ and nonsynonymous $\left(K_{\mathrm{a}}\right)$ substitutions.

\section{Results}

\section{Haplotype variations and saturation analysis}

We identified 99 haplotypes among the 102 Apodemus sylvaticus cytochrome $b$ sequences (GenBank accession numbers AJ511877 to AJ511987). The complete data matrix comprised these 99 haplotypes as well as two A. flavicollis and two A. mystacinus sequences used as outgroups, chosen on the basis of a molecular phylogenetic study on the genus Apodemus (Michaux et al. 2002). This matrix provided 965 base pairs, of which 282 sites (29\%) were variable and 226 (23\%) were parsimony informative. The mean transition to transversion ratio was 2.29 and the nucleotide frequencies were $26.3 \%, 30.5 \%, 30.7 \%$ and $12.5 \%$ for $C, T, A$ and $G$, respectively.
The saturation analysis showed that none of the events was affected by homoplasy with the exception of the transitions at the third codon position which showed a weak saturation ( $S=0.76$ and no plateau of saturation). However, as this substitution provided important phylogenetic information and as the use of weakly saturated events does not seems to interfere greatly in phylogenetic analyses (Yoder \& Yang, 2000), all the events were included in the analyses.

\section{Phylogenetic analyses}

The distance analysis (Fig. 2) showed that the $99 A$. sylvaticus haplotypes fell into two major clades: the first comprising the Italian, Balkan and Sicilian animals (clade 1 ), and the second corresponding to all the populations from North Africa and western, northern and central Europe (clade 2). These clades are well supported [bootstrap support (BP) of $97 \%$ and $88 \%$, respectively] and separated by a high degree of genetic divergence $(5.4 \%$ of K2P genetic distance). The first clade was divided into two subclades showing a large and robust differentiation (3.6\% K2P distance; BP: 100\%): a Sicilian one (subclade 1b) and an Italo-Balkan one (subclade 1a). A very well supported North African group (subclade 2a) (BP: 100\%; 1.9\% K2P distance) also appeared nested within the western European group (subclade $2 b$ ). No other geographical structure was observed with the exception of a weakly supported small subgroup (BP: 51/67) corresponding to Spanish and southern French animals (haplotypes 14-23). The MP analysis yielded one most parsimonious tree ( $L$ (number of parsimony steps $)=582$ steps; $C I$ (consistency index $)=0.53$; $R I($ retention index $)=0.89)$ identical to the NJ tree. The bootstrap values resulting from this analysis are included in Fig. 2. The minimum spanning network (Fig. 3) shows a high differentiation between clades 1 and 2 (22 mutational steps). The Sicilian and North African populations also appeared well separated with 17 and nine mutational steps, respectively. Subclades 1a and 2a appeared as starlike topologies, suggesting a recent expansion from a small number of animals (Avise, 2000) whereas subclades $1 \mathrm{~b}$ and $2 \mathrm{~b}$ appeared more heterogeneous.

\section{Nucleotide diversity and genetic structure}

We calculated nucleotide diversity for each subclade. Moreover, to assess whether nucleotide diversity was higher within the potential refuge regions compared to the northern populations, subclade $2 \mathrm{~b}$ was divided into two subgroups: the first corresponding to the Iberian and southern France populations and the second to all other European populations. The results of these analyses are summarized in Table 2 and indicate that the Sicilian animals have the highest level of nucleotide diversity. 


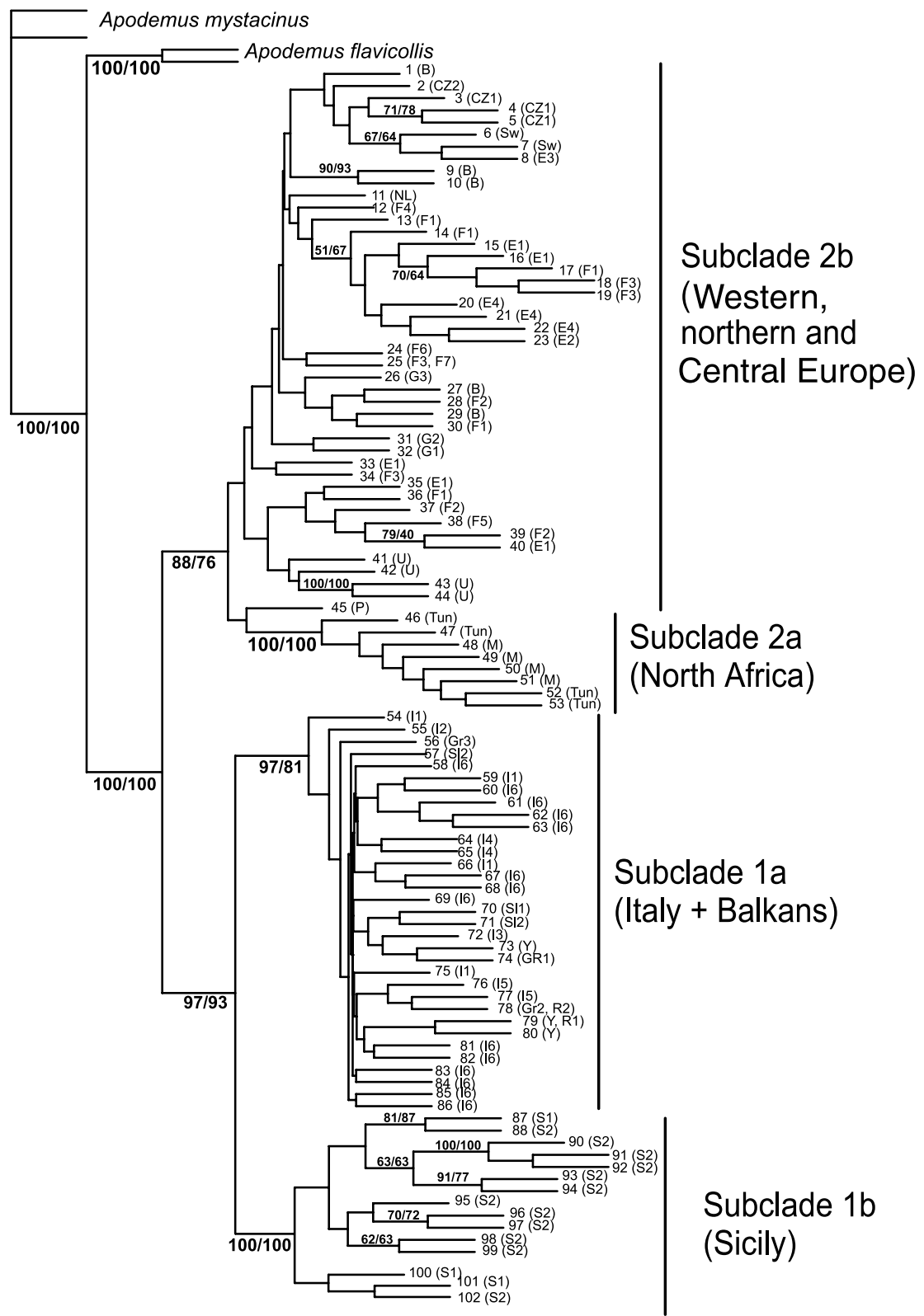

Fig. 2 Neighbour-joining tree for the 99 woodmouse mtDNA haplotypes (labelled from 1 to 99). Geographic origins (see Table 1 and Fig. 1) are shown in parentheses. Numbers indicated on the branches correspond to bootstrap support above $50 \%$ obtained in the NJ and MP analyses, respectively.
Within the continental populations, the southwestern group (subclade $2 \mathrm{~b} 1$ ) was characterized by a significantly higher nucleotide diversity $(P<0.05)$ than either the northern group (2b2) or the other subclades. Among these (1a, 2a), the North African population showed a very low level of nucleotide diversity.

The AMOvA showed that the majority of the total mtDNA variation $(76.2 \%)$ was distributed among the four genetic groups whereas a low percentage of this variation $(3.8 \%)$ was observed among populations within the main lineages.

A signature of population growth (i.e. a bell-shaped distribution) was clearly evident in the distribution of pairwise distribution within the subclades $1 a, 2 a$ and $2 b$
(Fig. 4). By contrast, a more heterogeneous distribution appeared in the Sicilian lineage (1b), suggesting a more stable population less subject to a recent expansion (Harpending et al. 1993). The coalescence analysis rejected the null hypothesis of a stable population for two subclades out of four: West Europe and North Africa. However, for Italy and Balkans (subclade 1a) the test was close to significance (Table 3). In all three cases the estimated population growth rate was positive, indicating an expansion for these subclades. For Sicily, there was no indication of population size change, and the null model was accepted. It is remarkable that the null hypothesis was rejected with the smallest sample size (North Africa), which suggests that the result for Sicily was not a result of lack of statistical power. 


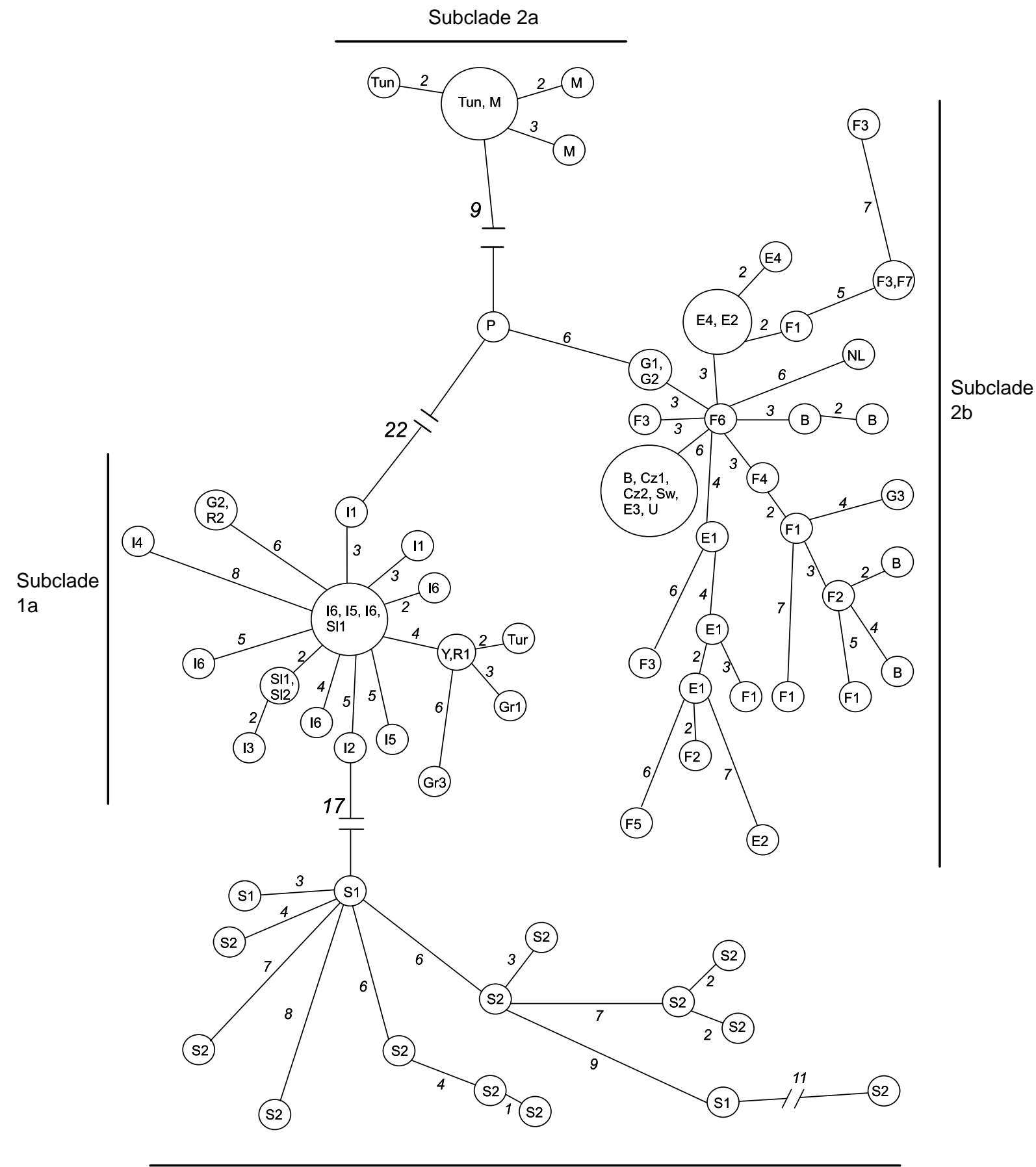

Subclade 1b

Fig. 3 A minimum spanning network constructed using mitochondrial cytochrome $b$ gene sequences. Geographic origins (see Table 1 and Fig. 1) are indicated. For simplicity, haplotypes separated by only one mutational step have been associated. Numbers in italics correspond to the mutational steps observed between haplotypes.

\section{Divergence time}

The relative rate test indicated no significant rate of heterogeneity (both $K_{\mathrm{s}}$ and $K_{\mathrm{a}}$ ) for cytochrome $b$ between the different $A$. sylvaticus subclades and the $A$. sylvaticus samples.
The mean K2P distance between $A$. mystacinus and $A$. flavicollis / A. sylvaticus that diverged $7 \mathrm{Myr}$ ago was $18.4 \%$. The distance between $A$. flavicollis and all remaining A. sylvaticus that diverged $4 \mathrm{Myr}$ ago was $11.4 \%$. These values gave a rate of $2.6-2.85 \% \mathrm{~K} 2 \mathrm{P}$ distance per million years 
Table 2 Genetic variability observed within the four main genetic lineages of Apodemus sylvaticus

\begin{tabular}{|c|c|c|c|c|c|c|c|}
\hline & Sample size & $\begin{array}{l}\text { No. of } \\
\text { haplotypes }\end{array}$ & $\begin{array}{l}\text { Genetic divergence } \\
\text { within each clade } \\
\text { (\% K2P distance) }\end{array}$ & $\begin{array}{l}\text { Nucleotide } \\
\text { diversity }\left(P_{i}\right)\end{array}$ & $\begin{array}{l}\text { Standard } \\
\text { deviation }\end{array}$ & $\begin{array}{l}\text { Haplotype } \\
\text { diversity }(h)\end{array}$ & $\begin{array}{l}\text { Standard } \\
\text { deviation }\end{array}$ \\
\hline \multicolumn{8}{|l|}{ Clade 1} \\
\hline Subclade 1a (Italy + Balkans) & 26 & 25 & 1.22 & 0.0064 & 0.0008 & 0.0968 & 0.022 \\
\hline Subclade 1b (Sicily) & 15 & 15 & 1.33 & 0.013 & 0.001 & 1 & 0.024 \\
\hline \multicolumn{8}{|l|}{ Clade 2} \\
\hline Subclade 2a (North Africa) & 8 & 8 & 0.29 & 0.0029 & 0.0005 & 1 & 0.063 \\
\hline Subclade $2 \mathrm{~b} 1^{*}$ (southern Europe) & 27 & 23 & 1.41 & 0.0087 & 0.0007 & 0.981 & 0.023 \\
\hline Subclade $2 \mathrm{~b} 2 *$ (northern Europe) & 26 & 20 & 1.09 & 0.0052 & 0.001 & 0.965 & 0.028 \\
\hline
\end{tabular}

*The subclade $2 b$ is divided into two different subgroups corresponding to the southern and northern European populations, respectively.

Table 3 Results of the coalescence analysis on the four main genetic lineages of Apodemus sylvaticus

\begin{tabular}{lllrll}
\hline & \multicolumn{2}{l}{ Log-likelihood } & & \\
\cline { 2 - 4 } & $\begin{array}{l}\text { stable } \\
\text { population } \\
\text { model }\end{array}$ & $\begin{array}{l}\text { exponential } \\
\text { change } \\
\text { model }\end{array}$ & & \\
\hline Sub-clades & $\chi^{2}$ & $P$ \\
\hline Italy, Balkans (1a) & -0.0028 & 1.6249 & 3.26 & 0.071 \\
Sicily (1b) & 0.0265 & 0.1142 & 0.18 & 0.675 \\
North Africa (2a) & 0.0035 & 2.2495 & 4.49 & 0.034 \\
West Europe (2b) & -0.1132 & 11.2927 & 22.81 & 0.0001 \\
\hline
\end{tabular}

(mystacinus/flavicollis-sylvaticus and flavicollis/sylvaticus). When this rate was applied to the different dichotomies within A. sylvaticus and taking into account the correction for ancestral mtDNA polymorphism, the following molecular datings were obtained: 1.5-1.6 Myr for the separation between clades 1 and 2, 0.8-0.9 Myr for the separation between clades $1 \mathrm{a}$ and $1 \mathrm{~b}$ (see Table 2) and 0.4 Myr for the separation of the North African population.

\section{Discussion}

\section{Association of geographical structure and historical} factors

The distance, maximum parsimony and network analyses clearly show that Apodemus sylvaticus populations are separated into four main genetic lineages that have nonoverlapping geographical distributions. These results are in agreement with those obtained on the basis of random fragment length polymorphism (RFLP) methods (Michaux et al. 1996a,b, 1998a,b; Libois et al. 2001). This geographical structure is highly supported as $76.2 \%$ of the total mtDNA variation (AMOva analysis, Table 3) is distributed among the four genetic groups. In contrast, as already observed on the phylogenetic trees, a smaller variability exists among populations within each of these lineages (3.8\% of total mtDNA variation).

Continental European populations are separated into two main lineages: the first one is widespread from southern Spain in the south to Sweden in the north and the Ukraine in the east; the second lineage is limited to Italy, the Balkans and the western part of Turkey. This strong geographical structure corresponds to the first category of phylogeographic model defined by Avise (2000). As already proposed for several other European species (Taberlet et al. 1998; Hewitt 2001; Seddon et al. 2001), this structure could be explained by isolation of two woodmouse groups in two different refugia (Iberian peninsula and Italy/Balkans) during one of the previous ice ages. This isolation was probably reinforced by the presence of the Alps which played, and probably continue to play, the role of a biogeographic barrier for the woodmouse (Michaux et al. 1996b). These two factors probably prevented genetic exchanges between both groups for a long time and led to the strong genetic differences observed within this species. In contrast, the frequent drops in the level of the Adriatic Sea during the Quaternary ice periods (Strahler \& Strahler 1989) probably allowed the Italian and Balkan woodmouse populations to remain in contact. Likewise, the population of woodmice found in western Turkey is very similar to that from the Balkans, suggesting recent contacts between them, probably during one of the last ice ages when the Marmara Sea was replaced by dry lands.

Do these lineages correspond to genetic groups within A. sylvaticus or to different species?

Johns \& Avise (1998) stated that cytochrome $b$ differentiation was highly congruent with traditional species boundaries. More recently, Bradley \& Baker (2001) used a partition of genetic distances values (using the K2P) in determining specific boundaries under the Genetic Species 


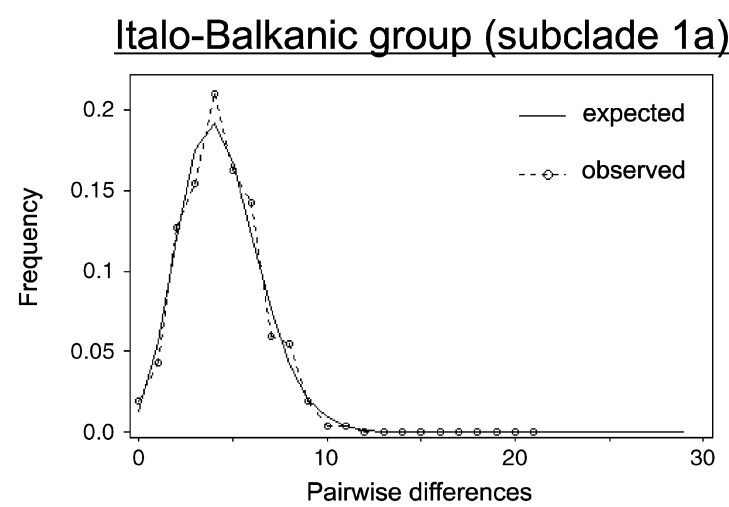

Sicily (subclade $1 b$ )

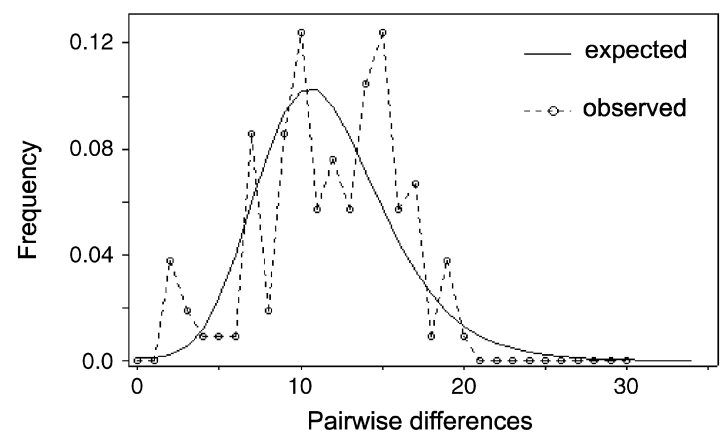

North Africa (subclade 2a)

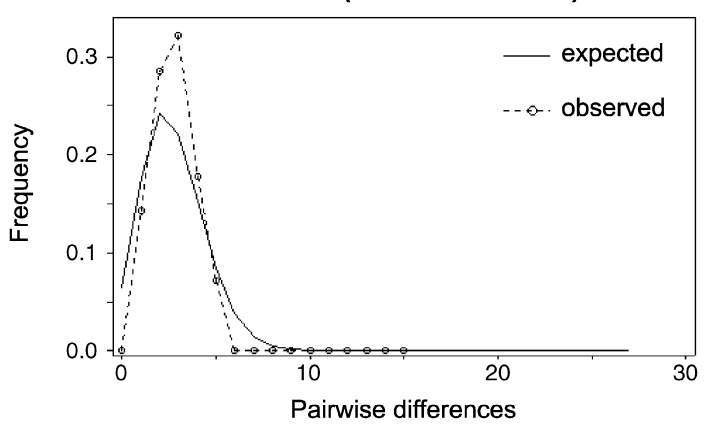

Main European lineage (subclade 2b)

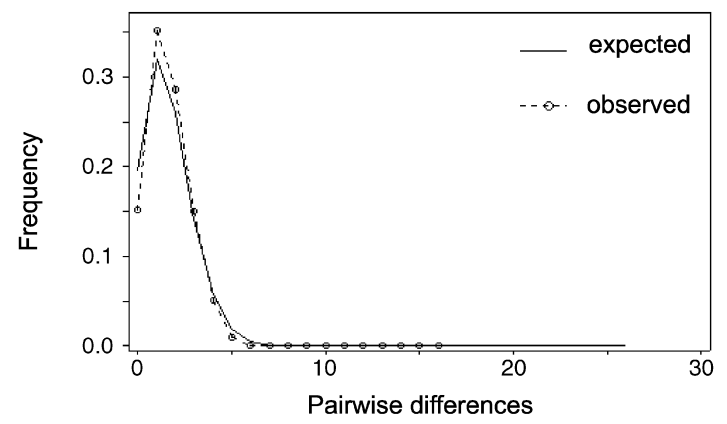

Fig. 4 Mismatch distribution for mtDNA types from the four major Apodemus sylvaticus genetic lineages. The expected frequency is based on a population growth-decline model (for the Italo-Balkan, Sicilian, North African and main European groups, respectively: $\theta$ initial $=0,2.4,0$ and $0, \theta$ final $=1000, \tau=4.4,9.4,2.7$ and 1.6), determined using the DNASP v3.5 program (Rozas \& Rozas 1997).
Concept. Taking this concept into account as well as previous data on rodents (Bradley \& Baker 2001), it seems that the level of genetic divergence between the different lineages of A. sylvaticus (maximum: $5.4 \% \mathrm{~K} 2 \mathrm{P}$ estimator) corresponds to different intraspecific genetic groups or subspecies. Indeed, the level of genetic divergence between $A$. sylvaticus and other closely related and welldefined species, such as A. flavicollis or A. alpicola, reaches at least 10-12\% (Michaux et al. 2002).

The divergence time estimated on the basis of two palaeontological calibration points, indicates a separation time of 1.5-1.6 Myr between the ancestral haplotypes which led to the two European lineages. Therefore, it appears that the intraspecific structure within $A$. sylvaticus developed during the Quaternary. This result is consistent with the hypotheses of Avise (2000), Seddon et al. (2001) and Hewitt (2001).

\section{Refuge regions and postglacial recolonizations}

As predicted by the expansion/contraction model (Nichols \& Hewitt 1994; Ibrahim et al. 1996; Santucci et al. 1998) the analysis of nucleotide diversity (Table 2) confirms that southwestern Europe (Iberian peninsula and southern France) was a refuge region for $A$. sylvaticus. Indeed, these populations are characterized by a genetic diversity significantly higher $(P<0.05)$ than in northern populations. Therefore, it is probable that woodmice recolonized and expanded in the main part of the Western Palearctic region from southwestern Europe at the end of the last ice age. This scenario of expansion is corroborated by a bell-shaped distribution in the mismatch distribution analysis for the main European lineage (Luikart et al. 2001). Thus, the Pyrenees were not an effective barrier to the northward expansion of the woodmouse (Michaux et al. 1998b). This does not confirm the assertion of Bilton et al. (1998) proposing that the widespread small mammal species did not recolonize northern Europe from the Mediterranean peninsulas. However, their hypothesis is not strongly supported by appropriate sampling $(n=1$ for each peninsula).

In contrast to the southwestern group, the Italo-Balkan populations are characterized by a lower genetic diversity. This observation is somewhat surprising as palaeontological (Aguilar and Michaux, unpublished data) and palaeoclimatological (Reille \& de Beaulieu 1995; Tzedakis et al. 1997) data attest that Italy and the Balkans were a refuge region for A. sylvaticus during the Quaternary glaciations. This low genetic variability could be explained by a genetic bottleneck which appeared during one of the last ice ages. This hypothesis is corroborated by three results: the very short branch lengths between haplotypes within this group in the distance analysis; the star-like topology in the minimum spanning network suggesting a rapid expansion 
from a small number of founder animals and a low value of haplotype $(h)$ and nucleotide $(\mathrm{Pi})$ diversity (Table 2) (Avise, 2000). The important decrease in population size could have resulted from different environmental factors:

(i) Palaeoclimatological data (Tzedakis 1994) indicate that a great part of the Balkans was more arid than the other western European regions during the early Quaternary glaciations. This climate probably influenced the distribution of the woodmouse habitat (woodlands) leading to a fragmentation of populations.

(ii) The number of closely related species of Apodemus ( $A$. flavicollis, A. uralensis, A. agrarius, A. mystacinus) is higher in Central Europe and the Balkans compared to western Europe (A. flavicollis and A. alpicola only in the Alps) (Schilling et al. 1986; Wilson \& Reeder 1993). Therefore, as these species often live in the same habitats, interspecific competition may have played a role in the decrease in population size and therefore of genetic variability of the woodmouse.

A genetic bottleneck could also explain why the ItaloBalkan populations did not contribute to the postglacial colonization of the northern regions, as expansion could only have occurred after population growth. During this time, the western group rapidly expanded towards northern and central Europe, thereby preventing a northern colonization by the Italo-Balkan animals. Indeed, once established, resident rodents often aggressively exclude newcomers (Granjon \& Cheylan 1989). Moreover, the presence of topographic obstacles such as the Alps and the Carpathian mountains might slow down a postglacial expansion of the Italo-Balkan group. This is the first report of such a pattern of postglacial colonization (Taberlet et al. 1998; Hewitt 1999, 2001).

\section{The 'Sicilian enigma'}

Until now, the origin of the Sicilian woodmouse population was unknown (Michaux et al. 1998). Our phylogenetic analyses indicate that they are related to the Italo-Balkan lineage. However, in contrast to the other western Mediterranean islands where the woodmouse was introduced recently and is genetically similar to continental populations (Michaux et al. 1996a,b, 1998b), the Sicilian lineage is very differentiated from the Italian ones $(3.2 \% \mathrm{~K} 2 \mathrm{P}$ distance). Their separation is estimated to have occurred 0.8 / $0.9 \mathrm{Myr}$ ago. The results, obtained with RFLP methods (Michaux et al. 1998), confirm this observation. Moreover, the mismatch distribution and the coalescent analyses show that this population was not subjected to a recent expansion but rather appears more stable than all the other European woodmouse populations (Harpending et al. 1993). A high value of $h$ and $P i$ corroborate this interpretation (Avise, 2000).

Two hypotheses can explain this:

(i) The Sicilian population has been isolated from the continent for at least $0.8 \mathrm{Myr}$ allowing ancestral haplotypes to survive and diverge whereas woodmice disappeared from continental regions for several reasons (i.e. genetic bottlenecks associated with more severe climate changes or interspecific competition). However, this hypothesis is at odds with the palaeontological and geological data which attest the presence of $A$. sylvaticus in Sicily for only 70 000-50 000 years (M. Sara, personal communication) and the existence of several connections between Sicily and Italy for the last million years (Thaler 1973; J. J. Jaeger, personal communication).

(ii) An old lineage could have survived elsewhere in southern Italy and entered Sicily during the last glaciation, 70000 years ago. This ancient stock would then have remained trapped on the island until present times where it suffered less from the last ice age climate, whereas the continental population was replaced by a modern stock spreading from other Italo-Balkan refuges during the postglacial era.

Whatever the hypothesis explaining the genetic differentiation of this population, Sicily appears as a 'hot spot' of genetic diversity for the woodmouse. This has also been observed for the bird Alectoris graeca (Lucchini \& Randi 1998).

\section{Colonization of northern Africa}

As already proposed by Libois et al. (2001) on the basis of RFLP methods, the phylogenetic analyses performed here show that the North African woodmice are clustered in a specific subclade $(100 \% \mathrm{BP})$ itself nested within the main European group (clade 2). This observation strongly suggests that the North African woodmice may have a southwestern European origin. This is supported by the absence of genetic affinities between the North African woodmice and either the Sicilian, Italian, or Balkan populations. The most closely related European haplotype (45) was found in the central part of Portugal, suggesting that their introduction probably occurred via the Strait of Gibraltar. The high value of $h$ and low value of $P i$ (Table 2), the mismatch distribution [bell-shape distribution (Fig. 4)], the coalescent results and the star-like topology observed in the minimum spanning network (Fig. 3) all suggest that the genetic structure of these woodmice is the consequence of the very recent introduction of a small number of animals followed by rapid population growth (Avise, 2000; Luikart et al. 2001). However, the divergence time analysis proposes a separation time (0.4 Myr: middle Pleistocene) between the European and North African population. 
This estimate is similar to that obtained on the basis of RFLP studies (Libois et al. 2001), but is at odds with the palaeontological data which suggest a recent (10 000 years: Holocene) colonization of the woodmouse in North Africa (Jaeger 1975; J. Jaeger, personal communication 1999; Burgio 1998) as well as the overall low genetic variability characterizing the North African woodmouse. This can be explained by two hypotheses:

(i) A recent colonization event involving only a few individuals may have occurred as a result of anthropogenic introductions (Michaux et al. 1996b, 1998; Dobson \& Wright, 2000). In this case, the relatively high level of genetic divergence between European and North African woodmice may be a result of the presence of divergent haplotypes in the introduced founder individuals. This is compatible with the high diversity of mitochondrial types observed in the Iberian region (Table 2).

(ii) A small initial 'inoculation' occurred during the middle Pleistocene period and only recently expanded. Nevertheless, it is difficult to explain why this founder population would not have invaded other North African regions during 400000 years, considering that the ecoclimatic characteristics of these regions were favourable for woodmice during the Pleistocene era (Jaeger 1975; Blondel 1995). Moreover, this hypothesis does not agree with the palaeontological data (Jaeger 1975).

In conclusion, we suggest that the woodmouse in North Africa originated from southwestern Europe and is probably the result of a recent anthropogenic introduction as has been suggested by Dobson (1998) and Dobson and Wright (2000).

\section{Acknowledgements}

We thank Drs Naomi Taylor, Janice Britton-Davidian and Bettine Jansen van Vuuren and two anonymous reviewers for their helpful comments on the manuscript. We thank François Catzeflis for providing tissue samples from the collection of ethanol-preserved tissues of the Institut des Sciences de l'Evolution (Montpellier) and all those people who provided tissue samples of rodent taxa: E. Bellinvia, J. Cassaing, S. Escutenaire, M-G. Filippucci, R. Fons, D. Frynta, P. Lymberakis, M. Macholan, S. Morand, D. Murariu, M. G. Ramalhinho, M. Sara., D. Sirugue, H. Tegelström, P. Trontelj, V. Vohralik and R. Wolf. This work was supported by a Belgian FNRS fellowship to J. R. Michaux (mandat 'Chargé de Recherches') and a financial grant of the Belgian FNRS (crédits aux chercheurs, crédits pour brefs séjours à l'étranger to J.R.M. and R.L.). This is contribution ISEM-2002-050 of the Institut des Sciences de l'Evolution de Montpellier (UMR 5554 CNRS).

\section{References}

Aguilar J-P, Michaux J (1996) The beginning of the age of Murinae (Mammalia: Rodentia) in southern France Acta zoologica Cracoviensa, 39, 35-45.
Alexandrino J, Froufe E, Arntzen JW, Ferrand N (2000) Genetic subdivision glacial refugia and postglacial recolonisation in the golden-striped salamander, Chioglossa lusitanica (Amphibia; Urodela). Molecular Ecology, 9, 771-781.

Avise JC (1994) Molecular markers, natural history and evolution. New York, Chapman \& Hall eds.

Avise JC (2000) Phylogeography The History and Formation of Species. Harvard University Press, Cambridge, MA.

Bilton DT, Mirol PM, Mascheretti S, Fredga K, Zima J, Searle JB (1998) Mediterranean Europe as an area of endemism for small mammals rather than a source for northwards postglacial colonization. Proceedings Royal Society London Biological Sciences, 265, 1219-1226.

Blondel J (1995) Biogéographie: Approche Écologique et Évolutive. Masson Ed., Paris.

Bradley RD, Baker RJ (2001) A test of the genetic species concept: cytochrome $\mathrm{b}$ sequences and mammals. Journal of Mammalogy, 82, 960-973.

Burgio E (1998) Le attuali conoscenze sui mammiferi terrestri quaternari della Sicilia. In: Prima Sicilia Alle Origini Della Società Siciliana (ed. Tusa. S), pp. 54-74. Il Naturalista Siciliano, Palermo (Sicily).

Catzeflis F (1991) Animal tissue collections for molecular genetics and systematics. Trends in Ecology and Evolution (TREE), 6, 168.

Dobson M (1998) Mammal distributions in the western Mediterranean: the role of human intervention. Mammal Review, 28, 77-88.

Dobson M, Wright A (2000) Faunal relationships and zoogeographical affinities of mammals in north-west Africa. Journal of Biogeography, 27, 417-424.

Edward SV (1997) Relevance of microevolutionary processes to higher level molecular systematics. In: Avian Molecular Evolution and Systematics (ed. Mindell DP), pp. 251-278. Academic Press, New York.

Emerson B, Paradis E, Thébaud C (2001) Revealing the demographic histories of species using DNA sequences. Trends in Ecology \& Evolution, 16, 707-716.

Engelbrecht CC, Freyhof J, Nolte A, Rassmann K, Schliewen U, Tautz D (2000) Phylogeography of the Bullhead Cottus gobio (Pisces: Teleostei: Cottidae) suggests a pre-Pleistocene origin of the major central European populations. Molecular Ecology, 9, 709-722.

Felsenstein J (1985) Confidence limits on phylogenies with a molecular clock. Systematic Zoology, 34, 152-161.

Fitch WM (1971) Towards defining the course of evolution: Minimum change for a specific tree topology. Systematic Zoology, 20, 406-416.

Granjon L, Cheylan G (1989) Le sort de rats noirs (Rattus rattus) introduits sur une île, révélé par radiotracking. Comptes Rendus Académie Des Sciences, Paris, 309, 571-575.

Harpending HC, Sherry ST, Rogers A, Stoneking M (1993) The genetic structure of ancient human populations. Current Anthropology, 34, 483-496.

Hassanin A, Lecointre G, Tillier S (1998) The 'evolutionary signal' of homoplasy in protein-coding gene sequences and its consequences for a priori weighting in phylogeny. Comptes Rendus Académie Des Sciences, Paris, Sciences Vie, 321, 611-620.

Hewitt GM (1996) Some genetic consequences of ice ages and their role in divergence and speciation. Biological Journal of the Linnean Society, 58, 247-276.

Hewitt GM (1999) Post-glacial recolonisation of European biota. Biological Journal of the Linnean Society, 58, 87-112. 
Hewitt GM (2001) Speciation, hybrid zones and phylogeography - or seeing genes in space and time. Molecular Ecology, 10, 537-549.

Ibrahim KM, Nichols RA, Hewitt G (1996) Spatial patterns of genetic variation generated by different forms of dispersal during range expansion. Heredity, 77, 282-291.

Jaarola M, Tegelstrom H (1995) Colonization history of north European field voles (Microtus agrestis) revealed by mitochondrial DNA. Molecular Ecology, 4, 299-310.

Jaeger JJ (1975) Les Rongeurs, du Miocène à l'actuel, en Afrique nordoccidentale. PhD Thesis, Université des Sciences et Techniques du Languedoc, Montpellier.

Johns GC, Avise JC (1998) A comparative summary of genetic distances in the vertebrates from the mitochondrial cytochrome $\mathrm{b}$ gene Molecular Biology and Evolution, 15, 1481-1490.

Kocher TD, Thomas WK, Meyer A et al. (1989) Dynamics of mitochondrial DNA evolution in animals: amplification and sequencing with conserved primers. Proceedings of the National Academy of Sciences, USA, 86, 6196-6200.

Kuhner MK, Yamato J, Felsenstein J (1995) Estimating effective population size and mutation rate from sequence data using Metropolis-Hastings sampling. Genetics, 140, 1421-1430.

Kuhner MK, Yamato J, Felsenstein J (1998) Maximum likelihood estimation of population growth rates based on the coalescent. Genetics, 149, 429-434.

Libois RM, Michaux JR, Ramalhinho MG, Maurois C, Sara M (2001) On the origin and systematics of the northern African wood mouse (Apodemus sylvaticus) populations: a comparative study of mtDNA restriction patterns. Canadian Journal of Zoology, 79, 1503-1511.

Lucchini V, Randi E (1998) Mitochondrial sequence variation and phylogeographical structure of rock partridge (Alectoris graeca) populations. Heredity, 81, 528-536.

Luikart G, Gielly L, Excoffier L, Vigne J-D, Bouvet J, Taberlet P (2001) Multiple maternal origins and weak phylogeographic structure in domestic goats. Proceedings of the National Academy of Sciences, USA, 98, 5927-5932.

Lunt DH, Ibrahim KM, Hewitt GM (1998) MtDNA phylogeography and postglacial patterns of subdivision in the meadow grasshopper Chorthippus parallelus. Heredity, 80, 633-641.

MacHordon A, Suarez J, Almodovar A, Bautista JM (2000) Mitochondrial haplotype variation and phylogeography of Iberian brown trout populations. Molecular Ecology, 9, 1324-1338.

Mardulyn P (2001) Phylogeography of the Vosges mountains populations of Gonioctena pallida (Coleoptera: Chrysomelidae): a nested clade analysis of mitochondrial DNA haplotypes. Molecular Ecology, 10, 1751-1763.

Merilae J, Bjoerklund M, Baker AJ (1997) Historical demography and present day population structure of the greenfinch, Carduelis chloris. An analysis of mtDNA control-region sequences. Evolution, 51, 946-956.

Mezhzherin SV, Zykov AE (1991) Genetic divergence and allozyme variability in mice genus Apodemus s. lato (Muridae, Rodentia). Cytology and Genetics, 2, 51-58.

Michaux J, Pasquier L (1974) Dynamique des populations de mulots (Rodentia, Apodemus) en Europe durant le Quaternaire. Premières Données Bulletins Société Géologique France, 7, 431-439.

Michaux J, Aguilar J-P, Montuire S, Wolff A, Legendre S (1997) Les Murinae (Rodentia, Mammalia) néogènes du Sud de la France: évolution et paléoenvironnements. Geobios, 20, 379-385.

Michaux JR, Libois R, Fons R (1996a) Différenciation génétique et morphologique du mulot, Apodemus sylvaticus, dans le bassin méditerranéen occidental. Vie Milieu, 46, 193-203.
Michaux JR, Filippucci MG, Libois RM, Fons R, Matagne RF (1996b) Biogeography and taxonomy of Apodemus sylvaticus (the woodmouse) in the tyrrhenian region: enzymatic variations and mitochondrial dna restriction pattern analysis. Heredity, 76, 267-277.

Michaux JR, Sara M, Libois RM, Matagne R (1998a) Is the woodmouse (Apodemus sylvaticus) of Sicily really a 'separate' species? Belgian Journal of Zoology, 128, 211-214.

Michaux JR, Libois R, Ramalhinho MG, Maurois C (1998b) On the mtDNA restriction patterns variation of the Iberian wood mouse (Apodemus sylvaticus). comparison with other west mediterranean populations. Hereditas, 129, 187-194.

Michaux JR, Chevret P, Filippucci M-G, Macholan M (2002) Phylogeny of the genus Apodemus with a special emphasis to the subgenus Sylvaemus using the nuclear IRBP gene and two mitochondrial markers: cytochrome $b$ and 12s rRNA. Molecular Phylogenetics and Evolution, 23, 123-136.

Nichols RA, Hewitt GM (1994) The genetic consequences of long distance dispersal during colonisation. Heredity, 72, 312-317.

Philippe H (1993) MUST, a computer package for Management Utilities for Sequences and Trees. Nucleic Acids Research, 21, 5264-5272.

Philippe H, Douzery E (1994) The pitfalls of molecular phylogeny based on four species as illustrated by the Cetacea/Artiodactyla relationships. Journal of Mammalian Evolution, 2, 133-152.

Pitra C, Lieckfeldt D, Alonso JC (2000) Population subdivision in Europe's great bustard inferred from mitochondrial and nulear DNA sequence variation. Molecular Ecology, 9, 1165-1170.

Reille M, de Beaulieu J (1995) Long pleistocene pollen records from the Praclaux Crater, South Central France. Quaternary Research, 44, 205-215.

Robinson M, Gouy M, Gautier C, Mouchiroud D (1998) Sensitivity of the Relative-Rate Test to Taxonomic Sampling. Molecular Biology and Evolution, 15, 1091-1098.

Rozas J, Rozas R (1997) DNASP, Version 2.0: a novel software package for extensive molecular population genetic analysis. Computer Application in the Biosciences, 13, 307-311.

Saitou N, Nei M (1987) The neighbor-joining method: a new method for reconstructing phylogenetic trees. Molecular Biology and Evolution, 4, 406-425.

Sambrook J, Fritsch EF, Maniatis T (1989) Molecular Cloning: A Laboratory Manual. Cold Spring Harbor Laboratory, Cold Spring Harbor, NY.

Santucci F, Emerson BC, Hewitt GM (1998) Mitochondrial DNA phylogeography of European hedgehogs. Molecular Ecology, 7, 1163-1172.

Schilling D, Singer D, Diller H (1986). Guide Des Mammifères d'Europe. Delachaux and Niestlé, Paris.

Schneider S, Roessli D, Excoffier L (2000) Arlequin, Version 2.0: a software for population genetic data analysis. Genetics and Biometry Laboratory, University of Geneva, Geneva.

Seddon JM, Santucci F, Reeve NJ, Hewitt GM (2001) DNA footprints of European hedgehogs, Erinaceus europaeus and E. concolor: Pleistocene refugia, postglacial expansion and colonization routes. Molecular Ecology, 10, 2187-2198.

Serizawa K, Suzuki H, Tsuchiya K (2000) A phylogenetic view on species radiation in Apodemus inferred from variation of nuclear and mitochondrial genes. Biochemicals Genetics, 38, 27-41.

Sharbel T, Haubold B, Mitchell-Olds T (2000) Genetic isolation by distance in Arabidopsis thaliana: biogeographie and postglacial colonisation routes of Europe. Molecular Ecology, 9, 2109-2118.

Strahler AH, Strahler AN (1989). Elements of Physical Geography, 3rd edn. John Wiley and Sons, New York. 
Suzuki H, Tsuchiya K, Takezaki N (2000) A molecular phylogenetic framework for the Ryuyku endemic rodents Tokudaia osimensis and Diplothrix legata. Molecular Phylogenetics and Evolution, 15, 15-24.

Swofford DL (1998) PAUP* Phylogenetic Analysis Using Parsimony ( ${ }^{*}$ and Other Methods), Version $40 \mathrm{~b}$ Sinauer Associates, Sunderland, MA.

Szymura JM, Uzell T, Spolsky C (2000) Mitochondrial DNA variation in the hybridizing fire-bellied toads Bombina bombina and B variegata. Molecular Ecology, 9, 891-899.

Taberlet P, Fumagalli L, Hausser J (1994) Chromosomal versus mitochondrial DNA evolution: tracking the evolutionary history of the southwestern european populations of the Sorex araneus group (Mammalia, insectivora). Evolution, 48, 623-636.

Taberlet P, Fumagalli L, Wust-Saucy AG, Cosson JF (1998) Comparative phylogeography and postglacial colonization routes in Europe. Molecular Ecology, 7, 453-464.

Thaler L (1973) Nanisme et gigantisme insulaire. La Recherche, 37, $76-83$.

Tzedakis PC (1994) Vegetation change through glacial - interglacial cycles: a long pollen sequence perspective. Philosophical Transactions of the Royal Society of London B, 345, 403-432.

Tzedakis PC, Andrieu V, de Beaulieu JL et al. (1997) Comparison of terrestrial and marine records of changing climate of the last 500000 years. Earth and Planetary Sciences Letters, 150, 171-176.
Widmer A, Lexer C (2001) Glacial refugia: sanctuaries for allelic richness, but not for gene diversity. Trends in Ecology and Evolution, 16, 269-271.

Wilson DE, Reeder DM (1993). Mammal Species of the World A Taxonomic and Geographic Reference. Smithsonian Institution Press, Washington and London.

Wu C-I, Li WH (1985) Evidence for higher rates of nucleotide substitutions in rodents than in man. Proceedings of the National Academy of Sciences, USA, 82, 1741-1745.

Yang Z (1996) Among-site rate variation and its impact on phylogenetic analyses. Trends in Ecological Evolution, 11, 367-372.

Yoder AD, Yang Z (2000) Estimation of primate speciation dates using local molecular clocks. Molecular Biology and Evolution, 17, 1081-1190.

Zagorodnyuk IV (1996) Sibling species of mice from Eastern Europe: taxonomy diagnostics and distribution. Proceeding of the National Academy of Sciences USA Russie, 12, 166-175.

This work forms part of a larger study performed by Johan Michaux and Roland Libois on the phylogeography of European forest mammal species. Elodie Magnanou is carrying out her thesis research on the island syndrome observed in the Mediterranean islands. 